\title{
Transmissão do Cowpea mild mottle virus pela mosca branca Bemisia tabaci biótipo B para plantas de feijão e soja.
}

\author{
Julio Massaharu Marubayashi ${ }^{1}$, Valdir Atsushi Yuki ${ }^{2}$ e Elaine Bahia Wutke ${ }^{3}$
}

${ }^{1}$ Departamento de Produção Vegetal, Faculdade de Ciências Agronômicas - UNESP, CP 237, CEP-18603-970, Botucatu-SP. ${ }^{2}$ Instituto Agronômico - IAC, CP 28, 13001-970, Campinas, SP. Parte da Dissertação de Mestrado do $1^{\circ}$ autor.

Autor para correspondência:Julio Massaharu Marubayashi (julio@fca.unesp.br)

Data de chegada: 25/02/2006. Aceito para publicação em: 10/02/2010.

\section{RESUMO}

Marubayashi, J.M.; Yuki, V.A.; Wutke, E.B.. Transmissão do Cowpea mild mottle virus pela mosca branca Bemisia tabaci biótipo B para plantas de feijão e soja.Summa Phytopathologica, v.36, n.2, p.158-160, 2010.

A necrose da haste da soja é causada por um vírus do gênero Carlavirus transmitido pela mosca branca Bemisia tabaci, também infectante de feijão e identificado como Cowpea mild mottle virus (CpMMV). Neste trabalho foram realizados testes para determinação do número de moscas-brancas B. tabaci biótipo B necessários para transmissão do vírus em feijoeiro e soja. $\mathrm{Na}$ sequência foram realizados dois outros testes, com 10 insetos por planta. Avaliaram-se períodos de acesso à aquisição (PAA) de 'Jalo' para 'Jalo', e o efeito de períodos de acesso à inoculação (PAI).
Foram visualmente constatados sintomas típicos do carlavírus como mosaico, clareamento de nervuras, necrose sistêmica e redução de crescimento. Houve transmissão do vírus para 'BT-2' de feijão e 'BRS-132' de soja com apenas um inseto por planta, sendo mais eficaz nesta última espécie. A taxa de transmissão do vírus foi maior com o aumento do número de insetos por planta. E o PAA foi determinado após 15' de tempo para aquisição, e o PAI com 5 min e aumentando os períodos de acesso a aquisição e inoculação aumentou-se a taxa de transmissão.

Palavras-chave adicionais: Carlavirus, vetor, Phaseolus vulgaris, Glycine Max, cultivares.

\section{ABSTRACT}

Marubayashi, J.M.; Yuki, V.A.; Wutke, E.B.. Transmission of the Cowpea mild mottle virus by whitefly Bemisia tabaci biotype B for plants of beans and soy. Summa Phytopathologica, v.36, n.2, p.158-160, 2010.

The stem necrosis of soybean is caused by a virus of the Carlavirus and transmitted for the whitefly Bemisia tabaci, also infectad of beans and identified as Cowpea mild mottle virus (CpMMV). In this work biotype B for transmission of the virus in beans and soy had been carried through tests for determination of the number of necessary whiteflys B. tabaci. In the sequence two other tests had been carried through, with 10 insects for plant. Periods of access to the acquisition (PAA) of 'Jalo' for 'Jalo', and the effect of periods of access to the inoculation (PAI) had been evaluated increase. Visually typical symptoms of carlavirus had been evidenced as mosaic, veinclearing, sistemic necrosis and reduction of growth. It had transmission of the virus for 'BT-2' of beans and 'BRS-132' of soy with only one insect for plant, being more efficient in this last species. The tax of transmission of the virus was bigger with the increase of the number of insects for plant. The PAA was after determined 15 min of time for acquisition, and the increase with $5 \mathrm{~min}$ and increasing the period of access the acquisition and inoculation increased it transmission tax.

Keywords:Carlavirus, vector, Phaseolus vulgaris, Glycine max, cultivars.

Cowpea mild mottle virus - CpMMV foi descrito no Brasil no ano de 1979, como um carlavírus infectante de plantas de feijão cultivar Jalo, com sintomas de mosaico em ângulos e mosaico amarelo internerval, e transmitido por mosca-branca com relação vírus-vetor não persistente (5). Entretanto na safra agrícola de 2000/2001 em culturas de soja do Centro Oeste do Brasil foram constatados sintomas de necrose da haste e morte de plantas, e nos anos seguintes foi constatada em outras regiões produtoras, a mais de $2000 \mathrm{~km}$ do foco inicial, e que a princípio pensava-se que a doença fosse causada por um fungo, mas posteriormente foi confirmado ser um vírus do gênero Carlavirus. Em estudos moleculares foi possível determinar similaridade de 84,8\% com o CpMMV acesso GenBank AF 024629 (1).

Esse vírus é semelhante ao CpMMV descrito por Brunt \& Kenten (2), como infectante de caupi (Vigna unguiculata (L.) e soja, com sintomas pouco acentuados de mosaico fraco e de enrugamento nas folhas. Na Costa do Marfin foi verificada relação vírus-vetor do tipo não persistente em testes de transmissão em soja com a B. tabaci(6).

Desse modo, o objetivo deste trabalho foi comprovar a transmissibilidade do vírus CpMMV pelo biótipo B da mosca branca (B. tabaci), mais agressivo e com mais fecundidade do que o biótipo A e atualmente predominante nas lavouras de feijão e soja, além de determinar o tipo de relação vírus-vetor nessas leguminosas.

O presente trabalho foi desenvolvido em insetários e em casa de vegetação do Setor de Virologia Fitotécnica do Centro de Pesquisa e Desenvolvimento de Fitossanidade do IAC, em 2005.

O primeiro isolado do CpMMV foi obtido em plantas de feijão 'Carioca', no Centro de Análise e Pesquisa Tecnológica do Agronegócio dos Grãos e Fibras do IAC. O vírus foi identificado pelo Prof. José Osmar Gaspar do Departamento de Zoologia e Botânica do Instituto 
IBILCE da UNESP, em São José do Rio Preto, SP.

Moscas-brancas isentas de fitovírus, da espécie Bemisia tabaci (Genn.) biótipo B, foram criadas em insetários, em plantas das cultivares Santa Cruz de tomate (Solanun esculentum Mill.) e Santa Rosa de soja.

Nos testes de transmissão insetos não víruliferos foram confinados em plantas de feijão 'Jalo', e de soja 'IAC-20' infectadas com o CpMMV, para período de acesso à aquisição (PAA) de $24 \mathrm{hs,} \mathrm{e} \mathrm{o}$ período de acesso à inoculação (PAI) de 48 hs. Com o auxílio de um aspirador manual, foram transferidos para plantas de feijão 'Jalo' e 'BT-2' e de soja 'BRS-132', cultivadas cada duas em vasos de barro e então protegidas com vidro de lampião, coberto na parte superior por tecido muito fino, evitando-se escape das moscas brancas. Em cada teste foram utilizadas 10 plantas, com três repetições.

Para o teste com diferentes números de insetos cerca de 1, 5, 10 e 20 insetos foram confinados em testes de transmissão, e para avaliar os períodos de acesso à aquisição (PAA) de 15', 30', 1h, 3hs, 6 hs e 24 hs, e período de acesso à inoculação (PAI) de 5,15 e 30 min e de 1, 2, 4 e 6 hs, cerca de 10 insetos foram transferidos para cada planta. Após o término do teste as plantas foram pulverizadas com inseticida para eliminação das moscas brancas e mantidas em casa de vegetação, por um mês, para as avaliações semanais.

Na Tabela 1 estão os resultados do experimento de transmissão de 'Jalo' para 'Jalo', de 'Jalo' para 'BT-2', e soja 'BRS-132'. Entre mesmos cultivares de feijão a taxa de transmissão foi nula com um inseto por planta, mas aumentando o número de insetos aumentou-se a transmissão para todas as combinações. As taxas percentuais de transmissão de 'Jalo' para 'Jalo' e de 'Jalo' para 'BT-2', podem ser consideradas similares e as diferenças detectadas com 10 insetos por planta, em ambas as situações, foi atribuída a uma variação experimental. Neste, com 10 insetos por planta a transmissão de 'Jalo' para 'Jalo' foi de $70 \%$, enquanto que, Costa et al. (4), utilizando 9 insetos, obtiveram apenas $44,7 \%$. O biótipo B dessa mosca branca, portanto, parece ser mais eficiente na transmissão do vírus do que o biótipo A.

Os sintomas da doença no feijoeiro 'Jalo' foram inicialmente clareamento das nervuras e mosaico, com posterior evolução para mosaico angular ou para manchas angulares, que são áreas verdes em um fundo amarelo em folhas mais velhas, limitadas pelas nervuras seguidas de redução de crescimento; esses mesmos sintomas também foram descritos por Costa et al. (4).

Nos testes de transmissão entre os cultivares de soja 'IAC-20' e 'BRS-132' (Tabela 1), os sintomas foram visualizados entre 8 a 15 dias da data de transmissão, sendo inicialmente um mosaico, enrugamento das folhas e deformação do limbo foliar, seguidos de acronecrose, curvatura e necrose do broto, necrose da haste, necrose do pecíolo e, por vezes, até a morte da planta. Com apenas um inseto por planta, a eficácia de transmissão para soja foi superior do que

Tabela 1 - Relação entre o número de insetos vetores (Bemisia tabaci biótipo B) e taxa de transmissão para plantas de cultivares de feijão e de soja infectadas pelo CpMMV.

\begin{tabular}{cccc}
\hline & \multicolumn{3}{c}{ \% Transmissão } \\
\cline { 2 - 4 } $\mathbf{N}^{\mathbf{0}}$ de insetos & $\begin{array}{c}\text { Jalo para } \\
\text { Jalo }\end{array}$ & $\begin{array}{c}\text { Jalo para } \\
\text { BT-2 }\end{array}$ & $\begin{array}{c}\text { IAC - 20 para } \\
\text { BRS-132 }\end{array}$ \\
\hline $\mathbf{1}$ & $0^{*}$ & 6,6 & 16,7 \\
$\mathbf{5}$ & 43,3 & 40,0 & 40,0 \\
$\mathbf{1 0}$ & 70,0 & 50,0 & 73,3 \\
$\mathbf{2 0}$ & 83,3 & 90,0 & 86,7 \\
\hline
\end{tabular}

Valor médio de três repetições; 24 horas de aquisição e 48 horas de inoculação. entre cultivares de feijão, entretanto, praticamente não houve diferença nos demais tratamentos.

Em testes de transmissão realizados por Muniyappa \& Reddy (5), utilizando B. tabaci Genn, os sintomas foram semelhantes aos descritos anteriormente e visualizados em até 10 dias da inoculação. Almeida et al. (1) obtiveram praticamente os mesmos resultados com o biótipo B da B. tabaci.

Os resultados dos testes com distintos períodos de acesso à aquisição do vírus CpMMV e de acesso à inoculação em feijão 'Jalo' estão na Tabela 2. Taxas médias de transmissão de $6,7 \%$ foram verificadas com PAA de 15', 30' e 1 hora, sendo crescentes até o PAA de 24 horas. Considerando o fato da rápida aquisição tão curto como o de 15', tem-se uma evidente indicação de ser esta uma relação vírusvetor do tipo não persistente.

Tabela 2 - Transmissão do Cowpea mild mottle virus (CpMMV) pela Bemisia tabaci biótipo $\mathrm{B}$ após diferentes períodos de acesso à aquisição (PAA) em feijoeiro Jalo.

\begin{tabular}{cc}
\hline PAA & \% Transmissão de Jalo para Jalo \\
\hline $\mathbf{1 5}$, & $6,7^{*}$ \\
$\mathbf{3 0}$, & 6,7 \\
$\mathbf{1}$ h & 6,7 \\
$\mathbf{3}$ hs & 36,7 \\
$\mathbf{6}$ hs & 33,3 \\
$\mathbf{2 4}$ hs & 63,3 \\
\hline
\end{tabular}

*Valor médio de três repetições; 48 horas de inoculação.

Em estudos de Muniyappa \& Reedy (5), foi demonstrada aquisição do CpMMV também de soja para soja, em períodos relativamente curtos de 10 minutos, evidenciando uma relação vírus-vetor do tipo não persistente.

Conforme os resultados das avaliações com distintos períodos de acesso à inoculação de 'Jalo' para 'Jalo' (Tabela 3), um PAI de 5 min já foi suficiente para a transmissão do CpMMV. A taxa de transmissão foi crescente até o período de $1 \mathrm{~h}$, sendo estabilizada entre os valores de $63,3 \%$ a $70 \%$ até PAI de 6 hs.

Tabela 3 - Transmissão do Cowpea mild mottle virus (CpMMV) pela Bemisia tabaci biótipo B após diferentes períodos de acesso à inoculação (PAI).

\begin{tabular}{cc}
\hline PAI & \% Transmissão de Jalo para Jalo \\
\hline $\mathbf{5}^{\prime}$ & $33,3^{*}$ \\
$\mathbf{1 5}$, & 53,3 \\
$\mathbf{3 0}$, & 60,0 \\
$\mathbf{1}$ h & 70,0 \\
$\mathbf{2}$ hs & 63,3 \\
$\mathbf{4}$ hs & 63,3 \\
$\mathbf{6}$ hs & 70,0 \\
\hline
\end{tabular}

*Valor médio de três repetições; 24 horas de aquisição.

Como considerado anteriormente, diante de um PAI tão curto como o de $5 \mathrm{~min}$, pode-se concluir por uma relação do tipo não persistente. Costa et al. (1983), em seus estudos de transmissão com um isolado do mesmo vírus verificaram transmissão do CpMMV para $12,5 \%$ das plantas de feijão 'Jalo'no PAI mais curto em teste de 15 min., com máximo de 50,0\% com 1 h. Ainda, em testes de transmissão de soja para soja com o CpMMV, Muniyappa \& Reedy (1983) obteve 
taxa de transmissão de $7 \%$ já com um PAI de 2 min e valor máximo de 83\% apenas com 20 min, e valores estáveis nos demais tratamentos. Nos resultados do presente trabalho e dos demais autores mencionados, coincidentemente o PAI é relativamente curto e o CpMMV pode ser transmitido em períodos curtos, de pelo menos até 5 minutos de alimentação após a aquisição do vírus.

\section{REFERÊNCIAS BIBLIOGRÁFICAS}

1. Almeida, A. M. R.; Piuga, F. F.; Marim, S. R. R.; Kitajima, E. W.; Gaspar, J. O.; Oliveira, T. G. \& Moraes, T. G. Detection and Partial Characterization of a Carlavirus Causing Stem Necrosis of Soybean in Brazil. Fitopatologia Brasileira, Fortaleza, v.2, n.30, p.191-194, 2005.
2. Brunt, A. A. \& Kenten, R. H. Cowpea mild mottle, a newly recognized virus infecting cowpeas (Vigna unguiculata) in Ghana. Annals of Applied Biology, Great Britain, v. 74, p.67-74, 1973.

3. Brunt, A. A. \& Phillips, S. Fuzzy vein, a disease of tomato (Lycopersicon esculentum) in Western Nigeria induced by cowpea mild mottle virus. Tropical Agricultural, Trinidad, v.58, n.2, p.177$180,1981$.

4. Costa, A.S.; Gaspar, J.O. \& Vega, J. Mosaico Angular do feijoeiro Jalo causado por um "carlavírus" transmitido pela mosca branca Bemisia tabaci. Fitopatologia Brasileira, Brasília, v.8, n.2, p.325-337, 1983.

5. Muniyappa, V. \& Reddy, D.V.R. Transmission of Cowpea Mild Mottle Virus by Bemisia tabaci in aNonpersistent Manner. Plant Disease, St. Paul, v.67, n.4, p.391 393, 1983.

6. Thouvenel, J. C.; Monsarrat, A. \& Fauquet, C. Isolation of $\mathrm{Co}$ wpea Mild Mottle Virus from Disease Soybeans in the Ivory Coast. Plant Disease, St. Paul, v.66, n.4, p.336-337, 1982. 